\title{
Trabalho e Adoecimento Psicossomático: Reflexões sobre o Problema do Nexo Causal
}

\author{
Laís Di Bella Castro Rabelo \\ Universidade Federal de Minas Gerais (UFMG), \\ $M G$, Brasil. \\ Julie Micheline Amaral Silva \\ Instituto René Rachou - Fiocruz Minas, MG, Brasil. \\ Maria Elizabeth Antunes Lima \\ Centro Universitário Novos Horizontes, MG, Brasil.
}

\begin{abstract}
Resumo: $\mathrm{O}$ artigo tem por objetivo trazer uma reflexão a respeito da relação entre fatores patogênicos presentes na organização de trabalho e o desenvolvimento de doenças psicossomáticas em trabalhadores, bem como os limites teóricos e metodológicos que envolvem a temática. Para tanto, apresenta o caso de uma trabalhadora do setor de teleatendimento que, em perícia na justiça do trabalho, recebeu a hipótese diagnóstica de episódio depressivo associado a um transtorno de somatização com desenvolvimento de doença autoimune, lúpus eritematoso sistêmico (LES). Do ponto de vista metodológico, trata-se de um estudo de caso, baseado no método biográfico. Por meio de uma interlocução com a literatura específica sobre o tema, propõe-se uma reflexão acerca das consequências da vivência do estresse laboral na saúde física e mental dos trabalhadores, especialmente sobre suas reverberações no sistema imunológico. Conclui-se por uma possível relação entre o adoecimento apresentado pela trabalhadora em questão e as exigências impostas pelo seu trabalho. Ressalta também a necessidade de mais estudos visando compreender melhor a passagem entre uma dada experiência de vida e a emergência de uma patologia específica.
\end{abstract}

Palavras-chave: Psicologia, Saúde do Trabalhador, Psicossomática.

\section{Work and Psychosomatic Illness: Reflections on the Problem of Causal Nexus}

\begin{abstract}
The purpose of this article is to reflect on the relation between pathogenic factors in work organization and the development of psychosomatic illness in workers, as well as the theoretical and methodological limits on the subject. It presents the case of a worker in the telemarketing sector who, in Labor Court, received a diagnostic hypothesis of depressive episode associated to a somatization disorder with the development of autoimmune disease, systemic lupus erythematosus (SLE). The methodology is a case study, based on the biographical method. Through an interlocution with the specific literature on the subject, it is proposed a reflection about the consequences of the experience of work stress on the workers' physical and mental health, especially on their repercussion in the immune system. It was concluded that there is a possible relation between the illness presented by the worker in question and the demands of the work performed by her. Also, the need to further studies to deepen the understanding of the passage between a life experience and the emergence of an specific pathology.
\end{abstract}

Keywords: Psychology, Occupational Health, Psychosomatic. 


\title{
Trabajo y Enfermedad Psicosomática: Reflexiones
} sobre el Problema del Nexo Causal

\begin{abstract}
Resumen: El artículo aborda la importancia de la relación entre los factores patógenos en la organización del trabajo y el desarrollo de enfermedades psicosomáticas en los trabajadores, así como las limitaciones teóricas y metodológicas que involucran el tema. Se presenta el caso de una empleada del sector de call center que, en pericia en el Tribunal del Trabajo, recibió diagnóstico de episodio depresivo asociado a un trastorno de somatización con el desarrollo de la enfermedad autoinmune, lupus eritematoso sistémico (LES). La metodología se trata de un estudio de caso, basado en el método biográfico. Por medio de una interlocución con la literatura específica sobre el tema, se propone una reflexión sobre las consecuencias de la experiencia del estrés laboral en la salud física y mental de los trabajadores, principalmente sus impactos en el sistema inmunológico. Se llegó a la conclusión de una posible relación entre la enfermedad presentada por la trabajadora con las exigencias del trabajo hecho por ella. También por la necesidad de más estudios para profundizar la comprensión con respecto a la pasaje de una experiencia de vida y la aparición de una patología específica.
\end{abstract}

Palabras clave: Psicología, Salud Ocupacional, Psicosomática.

\section{Introdução}

Desde seus primórdios, o campo de estudos em Saúde Mental e Trabalho (SM\&T) vem constatando o potencial patogênico de certas formas de organização do trabalho (Franco, Druck, \& Seligmann-Silva, 2010; Le Guillant, 2006; Maeno, \& Paparelli, 2013; Paparelli, Sato, \& Oliveira, 2011,). Nesse contexto, a perspectiva desenvolvida por Le Guillant (2006) propõe que os processos de adoecimento no contexto laboral sejam compreendidos através de um prisma de integralidade, pois a saúde não é percebida por ele como unicamente relacionada a fatores biológicos ou psíquicos individuais, sendo também mediada e contextualizada pelas práticas sociais presentes em uma dada organização do trabalho (Carloto, 2003). Assim, ao adotar essa perspectiva, entendemos a saúde como um fenômeno biopsicossocial no qual essas dimensões se integram e se afetam mutuamente.

Neste artigo, o objetivo maior consiste em refletir a respeito da pertinência da relação comumente estabelecida entre fatores patogênicos presentes na organização de trabalho e o desenvolvimento de doenças psicossomáticas em trabalhadores, tratando também dos limites teóricos e metodológicos que envolvem a temática. Para tanto, apresentamos o caso de uma trabalhadora do setor de teleatendimento, submetida a condições patogênicas de trabalho, baseada em exigências excessivas de resultados e rigidez das prescrições, que teve sua experiência de trabalho permeada pelo assédio moral, isto é, uma forma de tortura psicológica que se concretiza na repetição sistemática dos atos de humilhação, constrangimento e desqualificação (Barreto, \& Heloani, 2015). Sua hipótese diagnóstica recebida em decorrência de perícia psicológica na justiça do trabalho foi de episódio depressivo associado a um transtorno de somatização com desenvolvimento de lúpus eritematoso sistêmico (LES), uma doença autoimune.

A associação entre o trabalho no teleatendimento e o adoecimento psíquico tem sido descrita por pesquisadores, desde 1910. Nesse sentido, ao realizar seu estudo considerado um clássico em torno do tema, Le Guillant (2006), já citava as pesquisas de Julliard (1910), Fontègue \& Solari (1918) e Suzanne Pacaud (1949), nos quais relatavam que os trabalhadores do setor tinham uma alta incidência de perturbações de humor, marcadas por crises de choro, alteração no padrão de sono e fadiga nervosa.

No seu estudo, realizado com telefonistas das centrais telefônicas parisienses, em 1956, Le Guillant (2006) descreveu, juntamente com Jean Bégoin, um quadro que ficou conhecido como neurose das telefonistas. Foi identificada uma alta prevalência de um tipo de transtorno mental entre essas profissionais, caracterizado por alterações de humor e do caráter (como o surgimento de forte irritação, nervosismo e 
agressividade), entre outras manifestações somáticas, relacionadas, principalmente, à pressão sofrida pelas telefonistas durante sua jornada de trabalho. Em decorrência disso, a maioria relatou uma grande discrepância acerca de como se percebia antes e depois de sua inserção naquela profissão.

A conclusão foi a de que o nervosismo, a irritabilidade e a autoaceleração eram mantidos e perpetuados pela própria atividade, como um mal necessário, isto é, embora representasse algo negativo para as telefonistas, era interessante para a empresa, uma vez que as incitava a buscar uma produtividade exacerbada. Além dos distúrbios de sono e outros sintomas, observou-se a presença de um quadro de hiperemotividade e ansiedade latente, culminando, muitas vezes, em crises severas de "nervos". Dessa forma, profissionais mais nervosas eram também as mais produtivas, sendo que os sintomas permaneciam após a jornada de trabalho, contaminando sua vida pessoal (Le Guillant, 2006).

Ademais, a pesquisa revelou que, entre as telefonistas, era frequente o desenvolvimento de uma hipersensibilidade a ruídos, envolvendo, sobretudo, barulhos mais altos, bruscos e violentos, mas também aqueles repetitivos e monótonos, que passavam a ser absolutamente intoleráveis, desencadeando as crises nervosas (Le Guillant, 2006).

No Brasil, estudos vêm confirmando esses achados franceses, revelando sua atualidade e até mesmo, certo agravamento de alguns sintomas identificados pelos pesquisadores pioneiros. Eles apontam que o trabalho no teleatendimento configura-se como uma possibilidade efetiva de acesso dos jovens ao emprego forma, principalmente, os de baixa escolaridade e do gênero feminino. Embora as condições técnicas e materiais do trabalho no setor sejam muito diferentes daquelas analisadas pelos primeiros estudiosos do assunto, a organização de trabalho no setor permanece essencialmente patogênica, pois continua baseada em exigências excessivas de produtividade, no controle estrito do tempo e na baixa remuneração. Tudo isso configura um contexto claramente nocivo para a saúde desses trabalhadores (Barreto, 2001; Dieese, 2009; Dutra, 2014; Lucca, Zanatta, Rodrigues, Coimbra, Queiroz, \& Correa, 2014; Sato, Ramalho, Arruda, \& Hamilton, 2008; Venco, 2008).

O estudo realizado por Barreto (2001), por exemplo, apontou para um aumento da quantidade de aposentadorias entre profissionais do setor de telea- tendimento, motivadas por adoecimentos psíquicos e psiquiátricos, relacionados, sobretudo a quadros de depressão e ansiedade, que incluem, muitas vezes, algum tipo de dependência química. Esses dados relativamente antigos revelam a presença desses transtornos na categoria, desde períodos anteriores ao crescimento importante do setor de teleatendimento no país.

Posteriormente, outras pesquisas revelaram, entre os teleatendentes, a presença importante de sintomas como cansaço, esgotamento mental, tristeza e sentimento de impotência, em decorrência da rigidez excessiva da organização do trabalho nos call centers. (Machado, \& Ribeiro, 2016; Vilela, \& Assunção, 2004; Zillioto, \& Oliveira, 2014).

Portanto, embora tenha transcorrido um longo período entre as pesquisas francesas e as brasileiras, percebe-se uma forte semelhança entre os sintomas identificados, sugerindo que as mudanças consideráveis introduzidas no setor, sobretudo, com a introdução de inovações tecnológicas, não reduziram seus impactos negativos na saúde física e mental do teleatendente, podendo, ao contrário, tê-los agravado.

No caso que será discutido a seguir, a trabalhadora apresentou, de início, o quadro descrito anteriormente como neurose das telefonistas, atualmente denominado fadiga nervosa ou neurastenia (Brasil, \& Pan American Health Orgnaization, 2001). Contudo, ocorreu um agravamento progressivo dos sintomas, comumente associados ao estresse, isto é, irritabilidade excessiva, cefaleias e náuseas, que parecem ter afetado seu sistema imunológico. Pretendemos, assim, refletir sobre os possíveis nexos entre as condições de trabalho vividas por essa profissional, os sintomas de estresse e o quadro de LES.

O LES é uma doença reumatológica que causa inflamações em várias partes do corpo, sendo crônica, autoimune, de etiologia indefinida e ainda muito discutida, em especial, quanto às suas causas. De um lado, existem os autores que apontam os fatores genéticos como causas primárias do LES (Assis, \& Baklinni, 2009; Hahn, 2008), embora não existam estudos consistentes que confirmem tal relação. De outro, existem aqueles que relacionam as doenças autoimunes com os impactos do estresse no organismo, considerando-as como afecções psicossomáticas (Ballone, Pereira Neto, \& Ortolani, 2007; Mattje, \& Turato, 2006; Mello Filho, \& Burd, 2010). Portanto, este segundo grupo está mais respaldado pelas evidências científicas. 
De acordo com esses autores, as células do sistema imunológico sofrem influência dos sistemas nervoso e endócrino e o estresse age nestes sistemas ao gerar um aumento de secreção das substâncias conhecidas como catecolaminas (adrenalina e noradrenalina). As catecolaminas afetam as reações imunes de várias maneiras, inclusive, gerando a formação de anticorpos contra os constituintes do próprio organismo (Ballone et al., 2007; Mattje, \& Turato, 2006; Mello Filho, \& Burd, 2010; Nery, Borba, \& Lotufo Neto, 2004). Nesse sentido, a vivência de situações estressoras está vinculada à modulação do sistema imunológico, podendo, portanto, estar relacionadas às doenças autoimunes, como é o caso do LES.

Em uma pesquisa que acompanhou casos ambulatoriais de LES durante seis meses, relatada por Mello Filho e Burd (2010), constatou-se que a maior parte dos pacientes da amostra havia vivenciado situações de estresse, sendo que estas antecederam suas enfermidades ou contribuíram para sua exacerbação. Nery et al. (2004) apontam também que tanto reumatologistas experientes quanto os próprios pacientes frequentemente relacionam a piora ou o surgimento do LES com alguma situação de estresse.

Em seu estudo de revisão bibliográfica, Nery et al. (2004) indicam pesquisas que verificaram alterações na resposta imune em pacientes com LES, após exposição a um estressor psicológico agudo. Também relatam associações entre a exacerbação do LES com o aumento de estressores psicossociais.

\section{Método}

A pesquisa, de cunho qualitativo, foi realizada essencialmente através de um estudo de caso com uma operadora do setor de telemarketing que acionou judicialmente a empresa na qual trabalhava, alegando adoecimento causado pelo trabalho. Uma das autoras atuou como perita nomeada em juízo para verificar a existência (ou não) do nexo de causalidade alegado pela teleatendente.

A perícia foi pautada em uma abordagem multidimensional buscando-se a compreensão dos multiarticulantes, objetivos e subjetivos, individuais e coletivos, que compõem o processo de saúde e doença (Le Guillant, 2006; Vieira, Lima \& Lima, 2010). Para tanto, foram realizadas duas entrevistas em profundidade com a trabalhadora, além de entrevistas com familiares e profissionais de saúde relacionados ao caso, um estudo do local de trabalho e entrevistas com outros trabalhadores da empresa de teleatendimento. Essas etapas foram complementadas com um exame psíquico visando a avaliação das faculdades mentais com fundamento na perspectiva de Dalgalarrondo (2009). Realizou-se também, na perícia, um levantamento de evidências epidemiológicas, a partir da revisão de estudos em torno da categoria investigada. Por meio desse levantamento foi possível identificar quadros nosológicos associados a determinadas categorias profissionais (Le Guillant, 2006) e descrever características das enfermidades relacionadas ao caso.

A partir dos dados coletados e produzidos em função da perícia, realizou-se a pesquisa em tela. Vale ressaltar que os resultados alcançados no processo pericial são mais amplos do que aqueles que são destacados no escopo desse artigo. Os objetivos do estudo, bem como os métodos adotados, foram devidamente informados à trabalhadora, aqui identificada pelo nome fictício de Ana, que assentiu de forma livre e esclarecida sobre a utilização de sua perícia para produção de pesquisa científica. Considerou-se, portanto, o cuidado com a dignidade e a autonomia da participante, bem como a proteção de seus dados, impedindo sua identificação. Garantiu-se também que a pesquisa não traria a ela quaisquer malefícios.

A análise de dados obtidos no presente estudo foi inspirada da análise do discurso de linha francesa (Gadet, \& Hak, 1993, Pêcheux, 2002). Nessa perspectiva, considerando que a linguagem reflete a materialidade vivida, as falas da trabalhadora foram submetidas a uma análise vertical que possibilitou uma leitura interpretativa, ancorada na articulação entre a história singular e seu contexto sócio-histórico (Gadet \& Hak, 1993; Pêcheux, 2002).

Além disso, para reforçar a análise, foi exposto um estudo de caso publicado na França, em 2002, cuja problemática é semelhante àquela explicitada no presente artigo, permitindo uma maior compreensão de um tema reconhecidamente complexo.

\section{Resultados}

\section{A história de Ana}

Ana estava com 25 anos na ocasião das entrevistas, era casada e sem filhos. Segunda filha de uma família de três irmãos, afirmou se relacionar bem com a família e ter vivido uma infância tranquila:

Minha infância foi uma infância muito boa, muito tranquila. Cresci num sítio, então, assim, 
tinha contato com a natureza e tudo mais. Sempre fui muito tranquila [...] minha mãe nunca teve problema com meu pai, pra falar assim, separação, tudo mais ${ }^{1}$.

Conheceu o esposo na época em que trabalhava em uma escola e se casaram quando ela já atuava na empresa de teleatendimento. Relatou, inclusive, que não teve condições de organizar o próprio casamento devido ao excesso de trabalho, e foi sua mãe quem mais lhe ajudou. Descreveu uma boa relação conjugal e afirmou que, no período do seu adoecimento, o apoio do marido foi fundamental.

Em relação ao histórico clínico familiar, nenhum dos membros de sua família tem ou teve sintomas parecidos aos que ela apresentou em seu adoecimento, tendo sido investigado, inclusive, algum caso similar entre familiares distantes. Além disso, considerando seu histórico clínico pessoal, nunca apresentou manifestações sintomáticas parecidas com aquelas que desenvolveu durante o período em que trabalhou na empresa de teleatendimento.

Entre 16 e 18 anos, para complementar a renda familiar, Ana trabalhou com atividades como bordadeira de bolsas, vendedora de loja e professora particular de crianças e idosos em uma escola. Referiu-se a essas experiências de forma positiva, afirmando não ter passado por quaisquer problemas de saúde importantes nesse período.

Ao completar 18 anos, com o ensino médio já concluído, ela passou a procurar um trabalho com carteira assinada e foi contratada pela empresa de teleatendimento, sendo este, portanto, seu primeiro emprego formal, considerado essencial para sua manutenção.

\section{O trabalho na empresa de teleatendimento}

Ana foi admitida no início de 2008 por uma empresa de telefonia que prestava serviço terceirizado, na função de agente de cobrança. Ela foi realocada algumas vezes, saindo dos setores receptivos, isto é, aqueles em que o agente de cobrança recebe ligações dos clientes, sendo transferida para os setores ativos, nos quais os agentes são responsáveis por fazer ligações aos clientes e efetuar cobranças.
Sua jornada totalizava seis horas e 20 minutos diários, de segunda a sábado, tendo ainda um domingo mensal. Seu posto de trabalho era composto por um computador, um fone (headset) e uma cadeira, organizados em um espaço reduzido, consistindo em uma cabine denominada posto de atendimento (PA), sem contato direto com os colegas dispostos nas outras cabines.

De ponto de vista da sua organização, o trabalho era baseado em uma rígida prescrição, que impunha seguir à risca o $s c r i p t^{2}$ proposto pela empresa, já que a fidelidade ao prescrito era um dos critérios de avaliação e punição: "tinha aquele roteiro; se você saísse fora daquilo, tinha advertência".

\section{As pausas}

Ao longo da jornada diária de trabalho, Ana tinha direito a três pausas: uma com duração de 10 minutos, ao longo do dia, para ir ao banheiro, outra de 20 minutos para almoçar e uma terceira de 10 minutos para lanche. A pausa para o almoço era insuficiente até mesmo para aquecer a alimentação levada de casa, já que grande parte dos funcionários parava no mesmo horário e formavam-se filas grandes para usar os micro-ondas disponibilizados pela empresa. Diante dessa situação, muitas vezes, ela almoçava sem aquecer o alimento, pois, qualquer extrapolação no tempo previsto era, posteriormente, cobrada pelos supervisores: "então, você tem 20 minutos pra esquentar sua comida e comer; teve dia de eu ter que comer minha comida em dois minutos".

Constantemente, os supervisores controlavam as pausas para uso do banheiro por parte dos teleatendentes. Se algum permanecesse além de cinco minutos, o supervisor batia à porta ou mandava alguém ir até lá chamá-lo para retornar ao seu posto de trabalho. Caso não voltasse rapidamente, a pausa no sistema informático da empresa era suspensa pelo supervisor. Este possuía uma senha geral que permitia acesso a todos os usuários, de forma que as ligações eram direcionadas ao seu posto de atendimento mesmo quando o atendente ainda não havia retornado. Assim, o tempo de atraso e as ligações não atendidas eram contabilizados, resultando posteriormente, em advertências acompanhadas de ameaça de demissão por justa causa.

\footnotetext{
${ }^{1}$ As falas em itálico são transcrições literais das entrevistas. A inclusão das falas no presente artigo foi autorizada por Ana.

${ }^{2}$ Roteiro que prescreve as falas para serem ditas aos clientes pelo teleatendente.
} 
Além das pausas controladas, as ligações eram ininterruptas. Até mesmo quando o sistema informático da empresa estava com problemas, os atendentes continuavam a receber as chamadas, sendo obrigados a dizer aos clientes que não podiam atendê-los.

Assim, a jornada de trabalho sem qualquer intervalo, para além das pausas prescritas, não possibilitava atividades corriqueiras e básicas como, por exemplo, beber água ou ir ao banheiro fora do horário permitido.

\section{O sistema de metas}

A atividade realizada por Ana era baseada em cobranças por produção relacionadas ao número, qualidade e velocidade dos atendimentos. $\mathrm{O}$ não alcance das metas implicava em descontos nas comissões e a fiscalização constante dos supervisores configurava-se em uma fonte permanente de tensão, estresse e pressão:

Vocêé obrigada a cumprir metas, né? Têm as metas de atendimento e tudo o mais. [...] [As metas eram] atender o mais rápido possível, o maior número de pessoas. No que você vai negociar com o cliente, você num pode... não podia ficar negociando com ele. Eles te obrigam e você tem que ir passando pra frente. Menos tempo possível! Aí, você vai eliminando [...]. Acho que o que mais me afetou mesmo lá dentro é a questão dos supervisores.

Além disso, Ana era cobrada no sentido de obter sucesso nas negociações em torno do pagamento das dívidas pelos clientes, algo que estava fora do seu controle, especialmente, pela exigência de despender o menor tempo possível em cada atendimento, configurando uma espécie de paradoxo entre as exigências de tempo e qualidade: "de cada 10 pessoas que você fazia a cobrança, tinha um tanto estipulado pra você receber. [...] Você não podia ficar muito tempo com o mesmo cliente".

\section{$O$ adoecimento}

Segundo Ana, após aproximadamente sete meses de trabalho nessa empresa, começou a ter sintomas como cefaleias, náuseas e tonturas. Além disso, percebeu que estava mais agressiva e estressada, apresentando hipersensibilidade a ruídos, principalmente, aos toques de telefone. Na ocasião, até mesmo o ônibus, meio de transporte usado para ir ao trabalho, passou a ser rejeitado por ela, sendo que, ao avistá-lo, tinha ânsias de vômito.

Com o agravamento dos sintomas, ela passou a não conseguir realizar suas atividades com êxito, inclusive, tendo perdido a voz durante alguns atendimentos, o que gerou advertências, potencializando o estresse vivido na situação de trabalho.

Diante dessa situação, tentou negociar sua demissão. Contudo, após recusa da empresa, seus sintomas foram se acentuando, passando a invadir seu convívio social e familiar. Sobre isso, sua mãe afirmou: "cada dia que minha filha chegava em casa, chegava estressada. Eu olhava pra ela e não reconhecia. Falava: 'essa aí não é a Ana'”.

Ana decidiu, então, procurar ajuda médica, recebendo o diagnóstico de depressão e síndrome do pânico, mas sem receber afastamento previdenciário, nessa ocasião.

Após o diagnóstico, seu supervisor aconselhou-a a pedir férias, para tentar atenuar o problema. Ela acolheu a sugestão e relatou que seus sintomas desapareceram durante os 30 dias em que se ausentou da empresa. Mas, ao retornar, após aproximadamente uma semana de trabalho, a hipersensibilidade a ruídos, a irritabilidade e o estresse elevado começaram a se manifestar novamente: "quando eu voltei, os sintomas voltaram tudo de novo: quando eu colocava o fone, parecia que estava pegando fogo, minha orelha já ficava toda vermelha. E aquilo é como se tivesse dado uma alergia, sabe?".

\section{A situação "gota d'água"}

Ao regressar das férias, Ana tinha uma nova supervisora com quem tentou mais uma vez negociar sua demissão, em razão do retorno dos sintomas. Nessa ocasião, enfatizou que a supervisora aceitou demiti-la como uma espécie de prêmio por "bom comportamento", sendo que, em uma sexta-feira, pediu que fizesse logoff do sistema informático usado pela empresa e a acompanhasse até sua sala. Tal conduta era um código utilizado no ambiente de trabalho como prenúncio de demissão.

Pensando que seria demitida, Ana ficou extremamente contente, entretanto, ao chegar à sala da supervisora, ela lhe comunicou que havia mudado de ideia. Tal situação foi tão frustrante, que Ana a considerou como a "gota d'água" para o significativo agravamento dos seus problemas de saúde que veio a seguir: 
Eu me lembro que eu estava trabalhando, aí ela chegou perto de mime falou: "oh Ana, desloga e me acompanha por favor". E eu fiquei tão feliz, que eu não consegui, eu não consegui me conter. Fiquei... dava pra você ver, assim, o sorriso no meu rosto de longe [...]. Eu queria muito ser mandada embora, porque eu num tava aguentando mais trabalhar ali. Então, [...] peguei minhas coisas [...] e fui pra mesa dela. Ela olhou pra mim e falou assim: "cê tá feliz?" Falei: "tô". Eela: "porquêe" Eu: "porque cêvai me mandar embora". Ela: "'. Ela rasgou os papéis e jogou no lixo. E falou: "você pode voltar pro seu trabalho". Então, a partir daquele momento ali, eu acho que deu sabe?

\section{$O$ agravamento do quadro}

Um dia após o incidente com sua supervisora, Ana retornou ao trabalho e, ao chegar a sua casa, sentiu-se extremamente cansada, indo deitar-se. Ao acordar, sentiu as pernas enfraquecidas e relata não ter conseguido se levantar. Quando a situação se repetiu, em outra ocasião, a família decidiu levá-la ao serviço de saúde. Depois de realizar diversos exames, não foram diagnosticadas causas orgânicas para o sintoma apresentado. Ana ficou afastada do trabalho por 15 dias para sua recuperação, apesar disso, seu estado de saúde piorou, tendo perdido também os movimentos do corpo. Novamente, não ocorreu o afastamento previdenciário.

Ana buscou, mais uma vez, ajuda médica, iniciando um tratamento medicamentoso com antidepressivo, além de fazer uso de relaxantes musculares. $\mathrm{O}$ afastamento do trabalho foi prolongado por cerca de quatro meses quando recebeu seu primeiro afastamento previdenciário, que foi de fevereiro a junho de 2010, período no qual recuperou os movimentos do corpo.

Quando retornou ao trabalho, após três meses exercendo novamente suas atividades laborativas, Ana passou a sentir muitas dores e a apresentar manchas roxas nas pernas. Apesar das limitações impostas pelo novo problema de saúde, manteve-se no trabalho. Entretanto, após 15 dias, ficou impossibilitada de se deslocar até a empresa, época em que se constatou necrose de um dos dedos dos pés. Nesta ocasião, no início do ano 2011, ela se afastou novamente do trabalho e foi reencaminhada à previdência social, tendo recebido um auxílio-doença, que foi renovado por cinco vezes consecutivas.
A necrose levou ao diagnóstico de vasculite, doença que foi associada pelos médicos que a atenderam ao estresse e ao transtorno de pânico. Após esse diagnóstico, Ana não retornou mais ao trabalho. Mas, apesar do afastamento definitivo, os sintomas intensificaram-se e ela teve outros dedos dos pés necrosados, além da parte inferior das pernas comprometidas, resultando em cicatrizes permanentes. Foi internada por um período de quatro meses, sendo 15 dias no Centro de Terapia Intensiva (CTI), quando houve complicações graves do seu quadro, apresentando síndrome da angústia respiratória (SARA), com sério risco de morte.

Após os quatro meses de hospitalização, Ana ficou afastada do trabalho por cerca de três anos, durante os quais os benefícios previdenciários de auxílio-doença foram renovados consecutivamente. No decorrer do tratamento, em julho de 2011, foi diagnosticada com lúpus eritematoso sistêmico (LES). Em outubro de 2012, teve três de seus dedos dos pés amputados, mas, ainda assim, foi considerada novamente apta ao trabalho, pelo Instituto Nacional de Seguro Social (INSS), em março de 2013.

\section{O questionamento sobre a veracidade do adoecimento}

Durante o período em que trabalhou na empresa de teleatendimento, Ana passou por vários conflitos com seus supervisores sendo estes relacionados, principalmente, ao constante questionamento acerca da veracidade do seu adoecimento. Os atestados médicos, de modo geral, não eram bem recebidos pelos supervisores, que pressionavam os subordinados a não os apresentar, colocando em dúvida a autenticidade do documento e dizendo que estavam forçando um afastamento com intuito de não trabalhar.

Ana relatou também que durante seus afastamentos, inclusive quando estava internada, seus supervisores ligaram diversas vezes para sua casa e para o telefone celular de sua mãe, com o objetivo de pressioná-la a retornar ao trabalho, além de ameaçá-la de demissão:

Ele [o supervisor] já chegou a fazer 20, 30 ligações pra minha mãe em um só dia pra pedir minha mãe pra eu poder ir trabalhar [...]. Numa época em que eu fiquei internada eles me ligavam e me ameaçavam falando que iam me dar justa causa se eu não comparecesse na empresa. 
Ao ser entrevistada, sua mãe confirmou esse dado: "o supervisor sempre ligava pra mim e ficava falando que a Ana não queria trabalhar, que ela não ia achar um emprego melhor de que aquele".

\section{Os impactos psicossociais do adoecimento}

Ana foi demitida no início de 2013 e a empresa alegou justa causa. Segundo ela, o período em que trabalhou ali foi traumático, tendo acarretado consequências permanentes. Apesar de se sentir em condições para realizar novas atividades laborais após sua demissão, encontrou dificuldades para se reinserir no mercado de trabalho devido às deformações sofridas no corpo em decorrência do seu adoecimento.

Sentia-se constrangida com as deformações no corpo provocadas pela LES, enfatizando que seu convívio social mudou significativamente. Além das limitações físicas, Ana relatou que ainda persistiam alguns sintomas de ordem psíquica, principalmente, a tristeza, o desânimo e a hipersensibilidade a ruídos, porém, de forma mais branda se comparados ao período mais crítico do seu adoecimento. $\mathrm{O}$ quadro de LES encontrava-se estabilizado, não tendo se agravado após a saída da empresa.

Após algum tempo, Ana decidiu entrar com um processo judicial contra a empresa, tendo sido, inicialmente, inquirida por sua advogada sobre a possibilidade de reversão de sua demissão. Entretanto, ela recusou essa possibilidade, dizendo que jamais voltaria a trabalhar no setor de teleatendimento, preferindo abdicar do processo, caso esta fosse a única opção. Afirmou também que não recomendaria a qualquer pessoa o trabalho naquela empresa: "[...] você entra lá se você tiver passando fome, se você não tiver uma outra alternativa [...]. Eu acho que eu prefiro catar papelão no meio da rua do que voltar pra lá".

Decorridos nove meses após a realização da perícia, ao procurarmos Ana em busca de sua autorização para a publicação do presente artigo, ela já se encontrava em um novo emprego. Estava feliz, aparentando maiores cuidados com a própria imagem. Relatou que o LES estava estabilizado e que já não mais apresentava sintomas de depressão. O processo judicial foi solucionado por meio de um acordo com a empresa, uma vez que já não suportava mais aquela situação de conflito, que a obrigava a relembrar tudo o que passou, trazendo seu sofrimento à tona.

\section{Discussão do caso}

\section{Os indícios de um nexo de causalidade entre o trabalho e o adoecimento}

Durante o período em que trabalhou como teleatendente, Ana apresentou sintomas já identificados em estudos realizados com essa categoria profissional, tais como humor triste, diminuição do interesse ou prazer em atividades que normalmente são agradáveis, sintomas de ansiedade, alterações no padrão de sono, astenia, sendo que estes ocorreram em um contexto de trabalho envolvendo decepções sucessivas, alta exigência de desempenho e, ao final, pressão permanente pela sua demissão. Nesse sentido, verifica-se que seu adoecimento se enquadra na descrição do Manual de Doenças Relacionadas ao Trabalho (Brasil, 2001) acerca de episódios depressivos identificados em contextos laborais.

Embora as causas dos episódios depressivos sejam comumente ligadas ao funcionamento familiar, a algum transtorno de personalidade ou às comorbidades, como abuso de álcool (Piccoloto, Wainer, Benvegnú, \& Juruena, 2000), no seu caso não há quaisquer indícios da presença desses problemas. Pelo contrário, a história de Ana entra em consonância com a revisão de literatura em torno do adoecimento no setor de teleatendimento, conforme descrito na introdução deste artigo.

Ademais, Ana sofreu assédio moral caracterizado por pressões temporais excessivas; prescrições demasiadamente rígidas; cobranças por resultados que ultrapassavam suas possibilidades; questionamento da veracidade do seu adoecimento; controle abusivo do tempo de pausas, incluindo as idas ao banheiro; e cobrança da sua presença no trabalho nos períodos em que estava de licença médica.

Teixeira e Batistuti (2009), ao realizarem um estudo no setor, também identificaram o assédio moral relacionado ao mecanicismo da função de teleatendimento, marcada pela repetitividade dos processos, pelo ritmo intenso, controle excessivo, inclusive, em relação ao uso do banheiro, gerando uma relação conturbada com os supervisores. Além disso, ressaltaram que o assédio está relacionado ao impedimento sofrido pelo trabalhador no sentido de manifestar suas emoções, tendo que usar sua voz como um mero instrumento de trabalho. Os autores verificaram ainda que a pressão psicológica exercida no ambiente de teleatendimento gerou consequências sobre a mente e o corpo dos trabalhadores. 
Vieira, Lima e Lima (2012) reforçam essa visão ao considerarem que $o$ assédio moral no ambiente laboral relaciona-se à organização do trabalho que impõe exigências aos trabalhadores, sobretudo, por meio dos supervisores que reproduzem "uma manifestação particular das relações de poder e da violência entranhada na economia e nos processos de produção" (Vieira et al., 2012, p. 261).

As características da organização de trabalho vivenciadas por Ana na empresa de teleatendimento também foram identificadas nos estudos de Vilela \& Assunção (2004; 2005) acerca dos call centers. As autoras perceberam uma relação entre os mecanismos de controle do tempo, do conteúdo, do comportamento e do volume de serviços realizados nesta organização de trabalho e problemas de saúde mental apresentados pelos teleatendentes. Segundo as autoras, o sofrimento mental vivido por esses profissionais aparece como intermediário de um controle excessivo do corpo. Além disso, consideram que as condições de trabalho oferecidas pelo call center, de modo geral, não permitem o atendimento das exigências de produção e qualidade apresentadas por eles aos seus empregados, favorecendo ainda mais um ambiente de trabalho patogênico.

Tudo indica que, quando as cobranças impostas pelo trabalho se tornaram insuportáveis, o adoecimento de Ana permitiu que se afastasse, enfim, daquele ambiente. Segundo Canguilhem (2005; 2010), o adoecimento é, muitas vezes, uma saída involuntária e inconsciente encontrada pelo sujeito para conseguir sobreviver a uma situação demasiadamente penosa.

Todo o percurso de Ana sugere que sua aversão àquela forma de organização do trabalho gerou uma psicossomatização com consequências graves eirreversíveis. Seus sintomas que se iniciaram pelas náuseas e dores de cabeça evoluíram para o surgimento de manchas, perda de força nos membros inferiores, necrose dos dedos dos pés, vasculite, até chegar ao diagnóstico de LES.

A psicossomatização pode ser entendida, neste caso, como uma passagem da angústia vivenciada no contexto laboral para sintomas físicos. Esta é a nossa hipótese diagnóstica, reforçada pela ausência de qualquer histórico familiar positivo para a doença. O LES, como descrito no item anterior, é uma doença autoimune, que pode ser relacionada à psicossomática, principalmente no que se refere a uma resposta do organismo ao estresse. Neste sentido, há indícios expressivos de uma relação entre o desenvolvimento dessa afecção e as vivências estressantes impostas a Ana no ambiente de trabalho.

As significativas alterações na sua vida, principalmente, a fragilização do seu convívio social e a limitação das suas capacidades laborativas, deixam claro que as consequências desse trabalho em sua história foram avassaladoras. Atuando como um divisor de águas no seu modo de ser e agir, o trabalho no setor de teleatendimento, abalou sua saúde de forma evidente.

\section{Conclusões}

O caso exposto traz evidências importantes a respeito de uma possível relação entre organização de trabalho e adoecimento psicossomático, ou de forma mais precisa, entre o estresse laboral e o sistema imunológico. Não se trata de um nexo fácil de ser estabelecido e situações semelhantes são raramente descritas na literatura. Nesse sentido, encontramos o relato de um caso que pode auxiliar na compreensão da complexidade do que ocorreu com Ana. Trata-se do Sr. V., um paciente com câncer, atendido por uma médica do trabalho, na França (Chalons, 2003) ${ }^{3}$.

O Sr. V. sempre deixou claro que havia passado por situações demasiadamente estressantes no seu ambiente laboral. Seu câncer foi diagnosticado pelo seu médico como decorrente de uma infecção viral que teria favorecido o tipo de tumor que apresentava. No entanto, um comentário feito pelo médico responsável pela quimioterapia chamou sua atenção: "a maioria das pessoas que trata dessa patologia tem o mesmo perfil profissional; elas são muito estressadas". O Sr. V. levou esse comentário para a médica do trabalho, dizendo que ele também associava sua doença com o sofrimento que vivenciou no trabalho. Sua morte, algum tempo após essa consulta, foi um choque para a profissional e também para seus cole-

\footnotetext{
${ }^{3}$ Senhor V. era jornalista em um grande jornal parisiense e seus sintomas começaram após assumir o cargo de chefe da redação. Juntamente com a promoção ocorreu uma reorganização do trabalho no jornal, provocando nele um dilema moral, uma vez que envolvia a informatização de várias atividades exercidas pelos colegas, acarretando o desaparecimento de alguns profissionais cujos conhecimentos estavam na origem do próprio jornal. Ele se sentia culpado e, de certa forma, responsável pela supressão de vários empregos. Ademais, percebia que essas mudanças afetavam a qualidade e o valor do trabalho do jornalista. Passou a sofrer forte rejeição dos colegas, o que era fonte de enorme angústia, definida por ele, como uma "calamidade" que se abateu sobre sua vida. Enfim, deixou claro que não se sentia absolutamente preparado para a nova função.
} 
gas de trabalho, que passaram a procurá-la no seu consultório para exprimir sua dor e falar sobre os problemas ocorridos no jornal, após a promoção do Sr. V.

Ao conhecer esse caso, a psiquiatra Marie-Pierre Guiho-Bailly (2002) decidiu analisá-lo à luz dos conhecimentos acumulados a respeito da relação entre estresse e imunidade. Segundo ela, os experimentos em torno do tema têm se multiplicado a partir do desenvolvimento rápido de duas grandes correntes de pesquisa: a Psiconeuroimunologia e a Psicologia da Saúde. Ela se apoiou na primeira corrente para explicar o caso do Sr. V., uma vez que seu foco é a explicação das relações entre funcionamento cerebral e sistema imunitário, buscando, "objetivar a influência do estresse no desenvolvimento e evolução de certas patologias (alérgicas, infecciosas, cancerígenas, autoimunes)" (Guiho-Bailly, 2002, p. 183-184).

De acordo com a autora, "as interações entre o sistema nervoso (central e autônomo), sistema endócrino e sistema imunitário estão bem estabelecidas e conceituadas sob o termo de neuroimunomodulação", sendo que essas interações "funcionais, bidirecionais, são possíveis graças à existência de mediadores e receptores comuns aos três sistemas de integração do organismo". As abordagens neurobiológicas vêm aumentar a precisão em torno desses "mecanismos de intermodulações que são o controle de hormônios, de neuromediadores e de neuropeptídios". Ou seja, "dois sistemas neuroendócrinos (corticotrópico e catecolaminérgico) são identificados como 'eixos do estresse' e numerosos estudos tratam da correlação entre certos mecanismos cognitivo-afetivos com a ativação ou inibição desses eixos" (Guiho-Bailly, 2002, p. 184).

Portanto, esses estudos se referem "a um funcionamento mental definido por suas modalidades cognitivo-afetivas de adaptação a uma situação avaliada como estressante", a partir de uma "concepção multifatorial (biopsicossocial) da construção da imunidade e do desenvolvimento de certas patologias". Nesse sentido, ressalta a autora,

é interessante notar a evolução progressiva dos modelos de estresse em direção a um registro 'subjetivo' em torno das noções de 'estresse vivido', 'estresse percebido', levando em conta, em particular, o peso dos acontecimentos interpessoais, o sentimento de não poder enfrentar a situação, o sentimento de perda de controle e de alteração da autoestima (Guiho-Bailly, 2002, p. 184).
Em outras palavras, são aqueles acontecimentos vividos como um perigo para a própria existência e que impedem o sujeito de encontrar saídas ou de descarregar sua emoção pela ação ou expressão (Guiho-Bailly, 2002).

Enfim, as análises propostas por Guiho-Bailly (2002) a respeito do caso do Sr. V. nos permitem estabelecer um paralelo ao caso de Ana, pois fornecem elementos preciosos para compreendermos como se dá a passagem entre uma dada experiência de vida e a emergência de uma patologia específica (Le Guillant, 2006).

Por meio dessas análises, esperamos instigar novos estudos que aprofundem a compreensão sobre a relação entre certos tipos de adoecimento e determinadas formas de organização do trabalho. A identificação de mediadores entre experiências laborais potencialmente psicopatológicas, como aquelas que reportamos acima, e a emergência de doenças orgânicas é essencial, pois somente, a partir daí é que poderemos afirmar a existência de um nexo causal entre essas experiências e a patologia. No entanto, parece-nos inegável o paralelismo entre as vivências laborais relatadas por Ana e a emergência e agravamento dos seus sintomas, o que reforça a evidência de uma possível relação entre o contexto de trabalho e a doença psicossomática.

Os modos tradicionais e predominantes de pensar e atuar sobre as doenças e suas causas, tais como aqueles que restringem a etiologia do LES à predisposição genética, limitaram os diálogos possíveis neste estudo. Esse panorama dificulta o estabelecimento dos parâmetros para a compreensão do adoecimento de Ana como um processo de psicossomatização, além do nexo de causalidade entre os diversos sintomas que ela apresentou e as vivências no seu trabalho. Ademais, o campo de estudos sobre saúde dos trabalhadores traz questões demasiadamente complexas que exigem uma interdisciplinaridade que nos escapa nesse manuscrito. Nesse sentido, por meio deste artigo, tentamos também estimular uma reflexão crítica acerca da escassez de literatura especializada no assunto, e estimular estudos interdisciplinares que tratem da questão do nexo causal entre trabalho e adoecimento psicossomático. Esperamos, então, reverberar inquietações em torno de um tema frequentemente negligenciado, especialmente, pela carência de amparo teórico nas perspectivas biopsicossociais, que nos parecem as mais adequadas. 


\section{Referências}

Assis, M. R. D., \& Baaklini, C. E. (2009). Lúpus eritematoso sistêmico. Revista Brasileira de Medicina, 66(9), 274-285. Recuperado de http://www.moreirajr.com.br/revistas.asp?fase=r003\&id_materia=4087

Ballone, G. J., Pereira Neto, E., \& Ortolani, I. V. (2007). Da emoção à lesão: Um guia de medicina psicossomática (2a ed). Barueri, SP: Manole.

Barreto, F. L. (2001). O sofrimento psíquico e o processo de produção no setor de telefonia: Tentativa de compreensão de uma atividade com caráter patogênico (Dissertação de mestrado). Escola de Endgenharia, Universidade Federal de Minas Gerais, Belo Horizonte, MG.

Barreto, M., \& Heloani, R. (2015).Violência, saúde e trabalho: A intolerância e o assédio moral nas relações laborais. Serviço Social \& Sociedade, (123), 544-661. httpa://doi.org/10.1590/0101-6628.036

Brasil. Ministério da Saúde, \& Pan American Health Organization. (2001). Doenças relacionadas ao trabalho: Manual de procedimentos para os serviços de saúde (Série A. Normas e manuais técnicos, vol. 114). Brasília, DF, o autor. Recuperado de http://bvsms.saude.gov.br/bvs/publicacoes/doencas_relacionadas_trabalhol.pdf

Canguilhem, G (2005). Escritos sobre a medicina. Rio de Janeiro, RJ: Forense Universitária.

Canguilhem, G (2010). O normal e o patológico (6a ed). Rio de Janeiro, RJ: Forense Universitária.

Carloto, C. M. (2003). Adoecimento no trabalho, as mulheres na categoria de asseio e limpeza. Serviço Social em Revista, 1(6). Recuperado de http://www.uel.br/revistas/ssrevista/c_v6n1_cassia.htm

Chalons, A. (2003). Quand les mots perdent leur sens. Travailler, 1(9), 173-192. https:/ / doi.org/10.3917/ trav.009.0173

Dalgalarrondo, P. (2009). Psicopatologia e semiologia dos transtornos mentais. Porto Alegre, RS: Artmed.

Departamento Intersindical de Estatística e Estudos Socio-Econômicos - Dieese (2009). O emprego no setor de telecomunicações 10 anos após a privatização (Estudos e pesquisas, vol. 146). São Paulo, SP: o autor.

Dutra, R. Q. (2014). Do outro lado da linha: Poder Judiciário, regulação e adoecimento dos trabalhadores em Call Centers. São Paulo, SP: LTr.

Franco, T., Druck, G., \& Seligmann-Silva, E (2010). As novas relações de trabalho, o desgaste mental do trabalhador e os transtornos mentais no trabalho precarizado. Revista Brasileira Saúde Ocupacional, 35(122), 229-248. https://doi.org/10.1590/S0303-76572010000200006

Gadet, F., \& Hak, T. (1993). Por uma análise automática do discurso: Uma introdução à obra de Michel Pêcheux (2a ed.). Campinas, SP: Ed. Unicamp.

Guiho-Bailly, M. P. (2002). À propôs de "Quand les mots perdent leur sens” d’Annie Chalons. Travailler, 1(9), 183187. https://doi.org/10.3917/trav.009.0183

Hahn, B. H. (2008). Lupus Eritematoso Sistêmico. In A. S.Fauci, E. Braunwald, K. J. Isselbacher, J. B. Martin, D. L. Kasper, S. L. Hauser, \& D. L. Longo. Harrison medicina interna. (17a ed., pp. 2075-2083). Rio de Janeiro, RJ: McGraw-Hill.

Le Guillant, L. (2006) Escritos de Louis Le Guillant:Da ergoterapia à psicopatologia do trabalho. Petrópolis, RJ: Vozes.

Lucca, S. R. D., Zanatta, A. B., Rodrigues, M. S., Coimbra, I. B., Queiroz, F. S., \& Correa, B. (2014). Fatores de estresse relacionado ao trabalho: As vozes dos atendentes de telemarketing. Cadernos de Psicologia Social do Trabalho, 17(2), 290-304. Recuperado de http://www.revistas.usp.br/cpst/article/view/112349/110313

Machado, P. G. B., \& Ribeiro, P. J.V. (2016). O estresse em profissionais do setor de teleatendimento. Evinci, 1(4), 19391951. Recuperado de http://portaldeperiodicos.unibrasil.com.br/index.php/anaisevinci/article/view/1021/998

Maeno, M., \& Pararelli, R. (2013). O trabalho como ele é e a saúde mental do trabalhador. In M. A. Silveira (Org.), Inovação para o desenvolvimento de organizações sustentáveis: Trabalho, fatores psicossociais e ambiente saudável (pp. 145-166). Campinas, SP: Centro de Tecnologia da Informação Renato Archer.

Mattje, G. D., \& Turato, E. R. (2006). Experiências de vida com lúpus eritematoso sistêmico como relatadas na perspectiva de pacientes ambulatoriais no Brasil: Um estudo clínico-qualitativo. Revista Latino-Americana de Enfermagem, 14(4), 475-482. https://d=doi.org/10.1590/S0104-11692006000400002

Mello Filho, J.,\&, Burd, M.(2010). Psicossomática hoje. Porto Alegre, RS: Artmed. 
Nery, F. G., Borba, E. F., \& Lotufo Neto, F. L. (2004). Influência do estresse psicossocial no lúpus eritematoso sistêmico. Revista Brasileira de Reumatologia, 44(5), 355-361. https://doi.org/10.1590/S0482-50042004000500007

Paparelli, R., Sato, L., \& Oliveira, F. (2011). A saúde mental relacionada ao trabalho e os desafios aos profissionais da saúde. Revista Brasileira de Saúde Ocupacional, 36(123), 118-127. httpS://doi.org/10.1590/S030376572011000100011

Pêcheux, M. (2002). O discurso: Estrutura ou acontecimento (3a ed.). Campinas, SP: Pontes.

Piccoloto, N., Wainer, R., Benvegnú, L., \& Juruena, M. (2000). Curso e prognóstico da depressão. Revisão comparativa entre os transtornos do humor. Revista Psiquiatria Clínica, 27(2), 93-103.

Sato, L., Ramalho, C., Arruda, F., \& Hamilton, L. (2008). Viver na baia: dimensões psicossociais da saúde e do controle no trabalho de teleatendimento. Cadernos de Psicologia Social do Trabalho, 11(1), 19-39. Recuperado de http://www.revistas.usp.br/cpst/article/view/25788/27521

Teixeira, R. D. F., \& Batistuti, E. (2009). Assédio moral em organizações mecanicistas: efeitos em um call center. Revista Angrad, 10(2), 117-138. Recuperado de https://raep.emnuvens.com.br/raep/article/view/196/159

Venco, S. (2008). Quando o trabalho adoece: uma análise sobre o teleatendimento. INTERFACEHS, 3(3), artigo 1. Recuperado de http://www3.sp.senac.br/hotsites/blogs/InterfacEHS/wp-content/uploads/2013/07/art-12008-3.pdf

Vieira, C. E. C., Lima, F. P. A., \& Lima, M. E. A. (2012). E se o assédio não fosse moral? Perspectivas de análise de conflitos interpessoais em situações de trabalho. Revista Brasileira de Saúde Ocupacional, 37(126), 256-268. https:// doi.org/10.1590/S0303-76572012000200007

Vieira, C. E. C., Lima, F. P. A., \& Lima, M. E. A. (2010) O cotidiano dos vigilantes: Trabalho, saúde e adoecimento. Belo Horizonte, MG: Fumarc.

Vilela, L. V. D. O., \& Assunção, A. A. (2004). Os mecanismos de controle da atividade no setor de teleatendimento e as queixas de cansaço e esgotamento dos trabalhadores. Caderno de Saúde Pública, 20(4), 1069-1078. https://doi. org/10.1590/S0102-311X2004000400022

Vilela, L., \& Assunção, A. (2005). A atividade do teleatendente: Uma interface entre a organização do trabalho e o cliente (Dissertação de mestrado). Universidade Federal de Minas Gerais, Belo Horizonte, MG.

Ziliotto, D. M., \& Oliveira, B. O. D. (2014). A organização do trabalho em call centers: Implicações na saúde mental dos operadores. Revista Psicologia Organizações e Trabalho, 14(2), 169-179. Recuperado de http://pepsic.bvsalud.org/scielo.php?script=sci_arttext\&pid=S1984-66572014000200004

\section{Laís Di Bella Castro Rabelo}

Psicóloga. Perita Judicial no Tribunal Regional do Trabalho/3a região. Mestra e doutoranda em Psicologia Social na linhaTrabalho, SaúdeeSociabilidadepela UniversidadeFederal de Minas Gerais (UFMG), Belo Horizonte-MG. Brasil. E-mail: laisdibella@gmail.com

\section{Julie Micheline Amaral Silva}

Psicóloga pela Universidade Federal de Minas Gerais (UFMG/MG), Assessora em Perícia Judicial no Tribunal Regional do Trabalho/3a região, Belo Horizonte - MG. Brasil.

E-mail: julie.amaral50@gmail.com

\section{Maria Elizabeth Antunes Lima}

Psicóloga. Doutora em Psicossociologia do Trabalho pela Universidade de París-Dauphine (Paris IX), Paris, França. Professora titular aposentada na Universidade Federal de Minas Gerais (UFMG), Belo Horizonte - MG. Brasil. Atualmente, professora do Programa de Pós-Graduação do Centro Universitário Novos Horizontes, Belo Horizonte - MG. Brasil.

E-mail: antuneslima15@gmail.com 
Endereço para envio de correspondência:

R Califórnia 390, apto 101. Bairro Sion

CEP 30315500

Recebido 23/03/2017

Reformulado 01/09/2017

Aprovado 14/11/2017

Received $03 / 23 / 2017$

Reformulated $09 / 01 / 2017$

Approved 11/14/2017

Recibido 23/03/2017

Reformulado 01/09/2017

Aceptado 14/11/2017

Como citar: Rabelo L. D. B. C., Silva, J. M. A., \& Lima, M. E. A. (2018). Trabalho e adoecimento psicossomático: Reflexões sobre o problema do nexo causal. Psicologia: Ciência e Profissão, 38(1), 116-128. https://doi.org/10.1590/1982-3703000932017

How to cite: Rabelo L. D. B. C., Silva, J. M. A., \& Lima, M. E. A. (2018). Work and psychosomatic illness: Reflections on the problem of causal nexus. Psicologia: Ciência e Profissão, 38(1), 116-128. https://doi.org/10.1590/1982-3703000932017

Cómo citar: Rabelo L. D. B. C., Silva, J. M. A., \& Lima, M. E. A. (2018). Trabajo y enfermedad psicosomática: Reflexiones sobre el problema del nexo causal. Psicologia: Ciência e Profissão, 38(1), 116-128. https://doi.org/10.1590/1982-3703000932017 